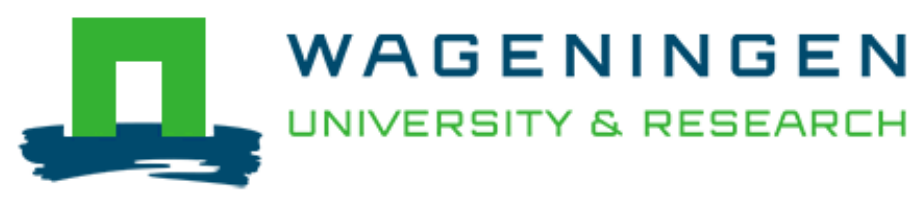

\author{
Fate and effects of triclosan in subtropical river biofilms \\ Zhang, N. S., Peng, F-J., Ying, G. G., \& van den Brink, P. J.
}

This is a "Post-Print" accepted manuscript, which has been published in "Aquatic Toxicology"

This version is distributed under a non-commercial no derivatives Creative Commons (c) (1) $\$(9$

(CC-BY-NC-ND) user license, which permits use, distribution, and reproduction in any medium, provided the original work is properly cited and not used for commercial purposes. Further, the restriction applies that if you remix, transform, or build upon the material, you may not distribute the modified material.

Please cite this publication as follows:

Zhang, N. S., Peng, F-J., Ying, G. G., \& van den Brink, P. J. (2019). Fate and effects of triclosan in subtropical river biofilms. Aquatic Toxicology, 212, 11-19.

https://doi.org/10.1016/j.aquatox.2019.04.015 


\section{Fate and effects of triclosan in subtropical river biofilms}

Naisheng Zhang ${ }^{\mathrm{a}, \mathrm{b}}$, Fengjiao Peng ${ }^{\mathrm{a}, \mathrm{b}}$, Guang-Guo Ying ${ }^{\mathrm{b}, \mathrm{c}}$, Paul J. Van den Brink $k^{\mathrm{a}, \mathrm{c}, \mathrm{d}}$

4

$5 \quad{ }^{a}$ Aquatic Ecology and Water Quality Management group, Wageningen University, P.O. Box 47, 6700 AA Wageningen, The Netherlands

${ }^{\mathrm{b}}$ State Key Laboratory of Organic Geochemistry, Guangzhou Institute of Geochemistry,

8 Chinese Academy of Sciences, Guangzhou 510640, China

${ }^{c}$ SCNU Environmental Research Institute, Guangdong Provincial Key Laboratory of Chemical Pollution and Environmental Safety \& MOE Key Laboratory of Environmental

${ }^{\mathrm{d}}$ Wageningen Environmental Research, P.O. Box 47, 6700 AA Wageningen, The

Netherlands

\section{Abstract}

Triclosan (TCS, 5-chloro-2-(2,4-dichlorophenoxy) phenol) is a broad-spectrum antimicrobial compound. Owing to its wide use, TCS has been frequently detected in river systems, especially in the (sub-)tropics. However, little information on its interaction with river biofilm in the (sub)tropics is currently available. In the present study, subtropical river biofilms were chronically exposed to TCS for $14 \mathrm{~d}$ at concentrations of $0.1-100 \mu \mathrm{g} / \mathrm{L}$ in artificial river water, which was followed by a $7 \mathrm{~d}$ recovery period. The results show that 100 $\mu \mathrm{g} / \mathrm{L}$ TCS inhibited the growth of river biofilms and the no-observed-effect concentration (NOEC) of TCS on river biofilms was $10 \mu \mathrm{g} / \mathrm{L}$. The affected biofilms did not completely recover within the $7 \mathrm{~d}$ of recovery period due to the adsorbed TCS which was not removed together with dissolved TCS. Exposure to TCS caused significant changes in prokaryotic species composition of river biofilms but no significant effects on eukaryotic species composition. In particular, the relative abundance of several TCS-tolerant bacterial species (e.g., Pseudoxanthomonas mexicana, Sphingopyxis alaskensis and Sphingomonas wittichii) in river biofilms increased following exposure to 10 and $100 \mu \mathrm{g} / \mathrm{L}$ TCS. River biofilm efficiently removed TCS from the liquid phase and the $\mathrm{pH}$ values of the aquatic system significantly affected the removal efficiency of TCS (from $36 \%$ at $\mathrm{pH} 6.5$ to $60 \%$ at $\mathrm{pH} 8.5$ ). No degradation products were detected in the liquid phase after 5 days of exposure, possibly due to strong adsorption of the hydrophobic degradation products to river biofilms and through biodegradation by bacteria utilizing TCS and its degradation products as source of 
aquaticum.

37 Keywords: Triclosan; River biofims; Sub-tropics; Growth inhibition; Community composition; Microorganisms

\section{Introduction}

River biofilms are assemblies of bacteria, algae, and fungi embedded in extracellular polymeric substances (Hall-Stoodley et al., 2004; Branda et al., 2005). They are important constituents of river ecosystems to maintain their function in terms of nutrient retention, producing organic substrates, feeding aquatic animals and organic matter re-mineralization (Huerta et al. 2016; Bechtold et al., 2012; Proia et al., 2012). In rivers and streams, biofilms consist of diverse species, have abundant biomass, are distributed ubiquitously, and are thereby exposed to and interact with various stressors.

Triclosan (TCS, 5-chloro-2-(2,4-dichlorophenoxy)phenol) is a broad-spectrum antimicrobial compound used in a wide range of consumer products i.e. antimicrobial soaps and body washes, toothpastes, cosmetics, clothing, kitchenware, furniture, and toys. As a typical emerging contaminant, TCS has been detected worldwide in rivers and lakes with concentrations up to $8.72 \mu \mathrm{g} / \mathrm{L}$ (Zhao et al., 2010; Ramaswamy et al., 2011; Cuderman and Heath, 2007; Perez et al., 2013; Zhang et al., 2015; Peng et al., 2017; Lehutso et al., 2017). Meanwhile, numerous studies have indicated the toxicological effects of TCS on aquatic communities. For instance, TCS possibly affects multiple target sites in different microalgal species which showed varying sensitivities to TCS (Franz et al., 2008). $7.9 \mathrm{mg} / \mathrm{kg}$ TCS in sediment increased the relative abundance of cyanobacteria and resulted in a dramatic die-off of algae within artificial streams (Drury et al., 2013). Besides, exposure to TCS at the concentration of $10 \mu \mathrm{g} / \mathrm{L}$ caused changes in bacterial community composition in river biofilms (Lawrence et al., 2009). In addition, Nietch et al. (2013) observed that stream periphytic biofilms were stimulated at low doses of TCS $(0.1,0.5$ and $1 \mu \mathrm{g} / \mathrm{L})$ but inhibited at high doses ( 5 and $10 \mu \mathrm{g} / \mathrm{L}$ ). The effects of TCS on river biofilm communities remained, even after a recovery period (Proia et al., 2011; Lawrence et al., 2015). However, most of the toxicological studies are limited to temperate regions, although the highest concentrations of TCS were detected in subtropical ecosystems (Zhang et al., 2015; Peng et al., 2017). A recent study performed in Thailand (Khatikarn et al., 2018) reported 96-h LC50 values for five invertebrate species ranging from 72 to $962 \mu \mathrm{g} / \mathrm{L}$ and concluded no significant difference between the sensitivity of aquatic species from tropical and temperate regions. Since algae proved to be more sensitive but hardly any (sub-)tropical data is available (Khatikarn et al., 2018), it is necessary to perform more studies using algal communities to provide a comprehensive understanding on the mechanism of TCS risks in (sub-)tropical freshwater systems. 
Biofilms play a vital role in water purification (Chenier et al., 2003; Tien and Chen, 2013) and use certain minerals and organic pollutants, resulting in a decrease in dissolved concentration of such pollutants in the water (Podda et al. 2014). Several studies have investigated the adsorption and degradation processes of TCS in freshwater environments. For example, the stable TCS concentrations in algae compared to the decreasing TCS concentration in the water phase implied a maximum adsorption ability of TCS to algae (Coogan et al., 2007). Higher sorption capacity of the sediment might reduce TCS bioavailability and its degradation rate in sediment (Huang et al., 2015). As to biodegradation, TCS can be degraded by both ammonia-oxidizing bacteria and heterotrophic microorganisms in activated sludge (Roh et al., 2009). Bacterial strains identified as Pseudomonas sp. are tolerant to TCS and can degrade TCS under aerobic, anoxic, and anaerobic conditions (Gangadharan Puthiya Veetil et al., 2012). However, little is known on how river biofilms can remove TCS from the overlying water phase, although 14C-triclosan studies have shown that only four to seven percent of the radioactive TCS was recovered sorbed to organic material or retained by the biofilm (Lawrence et al., 2015)..

To fill in the lack of data on the fate and effects of TCS on (sub-)tropical river biofilms, we exposed river biofilms to TCS using a range of concentrations $(0.1-100 \mu \mathrm{g} / \mathrm{L})$ including the concentrations of TCS occurring in natural sub-tropical river systems (Zhang et al., 2015; Peng et al., 2017; Lehutso et al., 2017). We evaluated the shifts in community structure and function using high-throughput sequencing and related statistical analyses. Additionally, we investigated the degradation of dissolved TCS by river biofilms under different $\mathrm{pH}$ conditions in terms of degradation rates and degradation products.

\section{Materials and methods}

\subsection{Culture of biofilm}

The chemical composition of artificial river water was adopted from Ylla et al. (2009) (12 $\mathrm{mg} / \mathrm{L} \mathrm{Na}_{2} \mathrm{SO}_{4}, 20 \mathrm{mg} / \mathrm{L} \mathrm{Na}_{2} \mathrm{SiO}_{3}, 30 \mathrm{mg} / \mathrm{L} \mathrm{CaCl}_{2}, 1 \mathrm{mg} / \mathrm{L} \mathrm{KCl}, 2 \mathrm{mg} / \mathrm{L} \mathrm{MgSO}_{4}$ and $20 \mathrm{mg} / \mathrm{L}$ $\mathrm{NaHCO}_{3}$ ) and was modified with the addition of $8 \mathrm{mg} / \mathrm{L} \mathrm{NH} 4 \mathrm{Cl}$ and $1.6 \mathrm{mg} / \mathrm{L} \mathrm{Na}_{3} \mathrm{PO}_{4}$ to simulate the eutrophication status of the sub-tropical river (Heng River, Boluo, Huizhou, China). The tap water which was used as solvent met the Standards for Drinking Water Quality in China (GB 5749-2006) and was aerated for more than $96 \mathrm{~h}$ before the artificial river water preparation.

The inoculum was collected from the submerged surface of about 10 rocks in Heng River and resuspended in the artificial river water of ca. $15 \mathrm{~L}$. Subsequently, 80 pieces of sandblasted glass slides $(2 \mathrm{~cm} \times 10 \mathrm{~cm})$ were placed into the water for 5 weeks for biofilm colonization. The water flow was driven by a mini-pump and kept under a controlled condition at $25{ }^{\circ} \mathrm{C}$ and a light intensity of 4000 lux with a dark/light cycle of $12 \mathrm{~h}$ : $12 \mathrm{~h}$. Half 
of the artificial river water was renewed every week until the surface of each slide was covered by green biofilm after 5 weeks.

\subsection{Toxicity experiment}

\subsubsection{Set-up of treatment and recovery}

Stock solutions were prepared by dissolving TCS (purity $99.5 \pm 0.5 \%$, QMX Laboratories Ltd., Essex, UK) in acetone (HPLC grade, Merck, Shanghai, China) and stored at $-20{ }^{\circ} \mathrm{C}$ before use. This toxicity experiment was conducted in $1 \mathrm{~L}$ beakers with four TCS treatments $(0.1 \mu \mathrm{g} / \mathrm{L}, 1 \mu \mathrm{g} / \mathrm{L}, 10 \mu \mathrm{g} / \mathrm{L}$ and $100 \mu \mathrm{g} / \mathrm{L} ; \mathrm{n}=4$ replicates $)$ and one acetone control $(\mathrm{n}=4)$. After adjusting the $\mathrm{pH}$ to $7.0 \pm 0.1$ using $1 \mathrm{M} \mathrm{HCl}$ and $1 \mathrm{M} \mathrm{NaOH}, 1 \mathrm{~L}$ of the artificial river water was spiked with $200 \mu \mathrm{L}$ of corresponding stock solution to obtain the initial TCS concentration in each replicate and the control received $158 \mathrm{mg} / \mathrm{L}$ acetone. Three colonized glass slides were dipped in each replicate and the artificial river water plus TCS was renewed every $48 \mathrm{~h}$. Following the14-day exposure period, there was a 7-day recovery period when the water was replaced by new artificial river water at $\mathrm{pH} 7.0 \pm 0.1$ every $48 \mathrm{~h}$.

\subsubsection{TCS extraction and analysis}

To determine TCS concentrations, $500 \mathrm{~mL}$ solution was sampled from each replicate after being spiked with the stock solution and the same was done before renewal to assess the decrease in TCS concentration. The TCS in the water samples collected from the toxicity experiment was extracted by solid phase extraction (SPE) method (Zhao et al., 2010).

Briefly, each sample was filtered through a $0.7-\mu \mathrm{m}$ glass fibre filter membrane, and extracted using an Oasis HLB cartridge $(500 \mathrm{mg}, 6 \mathrm{~mL}$ ) conditioned with methanol and water. The filtered water samples were passed through the cartridges at a flow rate of $5-10 \mathrm{~mL} / \mathrm{min}$. Each sample bottle was rinsed twice with two aliquots of $50 \mathrm{~mL}$ of $5 \%(\mathrm{v} / \mathrm{v})$ methanol in Milli-Q water, which also passed through the cartridge. After loading of water samples, the cartridges were dried under vacuum for $2 \mathrm{~h}$, and then eluted each with $7 \mathrm{~mL}$ of methanol and $5 \mathrm{~mL}$ of dichloromethane in sequence. The eluates were combined and dried under a gentle nitrogen stream, dissolved in $1 \mathrm{~mL}$ of methanol, filtered through a $0.22-\mu \mathrm{m}$ membrane filter into a 2-mL amber glass vial, and kept at $-20{ }^{\circ} \mathrm{C}$ before the instrumental analysis.

An Agilent 1200 series high performance liquid chromatograph (HPLC) fitted with a diode array detector was used for the analytical verification (Yang et al., 2011). Briefly, a SGE C18 RS column $(100 \times 4.6 \mathrm{~mm}, 5 \mathrm{~m})$ with a guard column $(\mathrm{C} 18,4.6 \times 7.5 \mathrm{~mm}, 5 \mathrm{~m})$ was used for the separation of TCS. Acetonitrile (ACN, HPLC grade, Merck, Shanghai, China) and Milli-Q water (Millipore, Watford) with $0.1 \%$ acetic acid were used as the mobile phase, which was programmed at $70 \% \mathrm{ACN}$ for $6.5 \mathrm{~min}$ followed by a post time of $2 \mathrm{~min}$. The injection volume was $100 \mu \mathrm{L}$ and the flow rate was set at $1 \mathrm{~mL} / \mathrm{min}$. The UV wavelength for detection was $205 \mathrm{~nm}$. The retention time for TCS was $5.0 \mathrm{~min}$. The instrumental limit of quantification (LOQ) for TCS was $5 \mu \mathrm{g} / \mathrm{L}$ and the limit of detection 


\subsubsection{Biomass and chlorophyll-a}

At the beginning of exposure (Day 0), biofilm samples were collected from four additional replicates which were not exposed to TCS. By the end of exposure (Day 14) and recovery (Day 21) periods, biofilms were scraped from randomly selected glass slides from each replicate. Specifically, a $18 \mathrm{~cm}^{2}$ of biofilm sample was taken for biomass measurement and a $12 \mathrm{~cm}^{2}$ for photosynthetic pigment determination.

To measure biomass (dry weight, DW), biofilm samples were dried at $80^{\circ} \mathrm{C}$ for more than $4 \mathrm{~h}$ until constant weight was obtained using an electronic balance. To extract the photosynthetic pigment, a previously described method was adopted (Peng et al., 2014). Briefly, biofilm samples were frozen $\left(-20^{\circ} \mathrm{C}\right)$ for $20 \mathrm{~min}$ and thawed $\left(25^{\circ} \mathrm{C}\right)$ for $5 \mathrm{~min}$, which was repeated three times and followed by being frozen $\left(-20^{\circ} \mathrm{C}\right)$ overnight until the cell walls were broken. The processed biofilm was suspended in 95\% ethyl alcohol, heated at $80{ }^{\circ} \mathrm{C}$ for $2 \mathrm{~min}$, and then kept static for $6 \mathrm{~h}$ at room temperature. After centrifugation for 5 $\min$ at 5,445g, the absorbance values of the supernatant at $665 \mathrm{~nm}\left(\mathrm{~A}_{665}\right)$ and $649 \mathrm{~nm}\left(\mathrm{~A}_{649}\right)$ within the measurement range of the spectrophotometer were detected and chlorophyll-a $\left(\mathrm{C}_{\mathrm{A}}\right)$ content was calculated according to:

$\mathrm{C}_{\mathrm{A}}(\mathrm{mg} / \mathrm{L})=13.95 \mathrm{~A}_{665}-6.88 \mathrm{~A}_{649}$

\subsubsection{Molecular endpoints}

For molecular analyses, a $20 \mathrm{~cm}^{2}$ of biofilm sample was collected from each replicate at 3 time points (Day 0, Day 14 and Day 21) according to the same protocol of paragraph 2.2.3 and stored at $-80{ }^{\circ} \mathrm{C}$.

Total genome DNA of biofilm was extracted using the CTAB/SDS method (SaghaiMaroof et al. 1984; Dellaporta et al. 1983). 16S rRNA/18SrRNA genes of distinct regions (16SV4/16SV3/16SV3-V4/16SV4-V5, 18S V4/18S V9) were amplified using specific primers (e.g. 16S V4: 515F-806R, 18S V4: 528F-706R, 18S V9: 1380F-1510R, et al.) with the barcode. All PCR reactions were carried out with Phusion ${ }^{\circledR}$ High-Fidelity PCR Master Mix (New England Biolabs). The same volume of 1X loading buffer (contained SYB green) was mixed with PCR product in equidensity ratios and electrophoresis was operated on $2 \%$ agarose gel for detection. Samples with bright main strip between 400-450 bp were chosen for further experiments. Then, PCR product was purified with Qiagen Gel Extraction Kit (Qiagen, Germany).

Sequencing libraries were generated using TruSeq ${ }^{\circledR}$ DNA PCR-Free Sample Preparation Kit (Illumina, USA) following manufacturer's recommendations and index codes were added. The library quality was assessed on the Qubit@2.0 Fluorometer (Thermo Scientific) and Agilent Bioanalyzer 2100 system. Lastly, the library was sequenced on an 
Illumina HiSeq2500 platform and 250 bp paired-end reads were generated.

Sequences analyses were performed by Uparse v7.0.1001 (http://drive5.com/uparse/) (Edgar, 2013). Sequences with $\geq 97 \%$ similarity were assigned to the same operational taxonomic units (OTUs). Representative sequence for each OTU was screened for further annotation based on the GreenGene Database (http://greengenes.lbl.gov/cgi-bin/nphindex.cgi) and RDP classifier v2.2 (http://sourceforge.net/projects/rdp-classifier/) (Wang et al., 2007). OTUs abundance information was normalized using a standard of sequence number corresponding to the sample with the least sequences.

\subsubsection{Statistical analyses on toxicity endpoints}

To compare the differences of biofilm response between the TCS treatments and the control in the toxicity experiment, the Williams tests (Williams, 1972) were carried out to determine the no-observed-effect concentrations (NOECs) of TCS based on the untransformed data of dry weight, chlorophyll-a content and their ratio $\left(\mathrm{C}_{\mathrm{A}} / \mathrm{DW}\right)$. The analyses were performed with the Community Analysis computer program version 4.3.05 (Hommen et al., 1994) using a significance level of 0.05.

The community composition of each sample was summarized and compared based on the top 10 relative abundance data at the levels of phylum, class, order, family, genus and species. Meanwhile, the total relative abundance data at the species level were arcsine transformed for principle response curve (PRC) analyses in Canoco 5.1 (Van den Brink et al., 1999; Ter Braak and Smilauer, 2012). The PRC method, based on redundancy analysis (RDA), shows the effects of chemical stress on community response over time compared to control test systems (Miranda et al., 2018). The principal component was plotted against time, yielding a principal response curve of the community for each treatment.

To assess the significance of the effects of TCS concentrations on the biofilm community composition, RDA analyses accompanied with Monte Carlo permutation tests were also performed per sampling date for the relative abundance dataset testing each treatment separately against the control.

\subsection{TCS degradation experiment}

\subsubsection{Set-up of degradation systems}

$1 \mathrm{~L}$ of artificial river water was spiked with $200 \mu \mathrm{L}$ of TCS stock solution to obtain the final concentration of $100 \mu \mathrm{g} / \mathrm{L}$ in each beaker. Replicated $(\mathrm{n}=3)$ treatments containing five $\mathrm{pH}$ regimes were established by respectively adjusting their $\mathrm{pH}$ values to $6.5,7.0,7.5,8.0$, and 8.5, as described in paragraph 2.2. Three colonized glass slides were dipped into each replicate. As a negative control, clean glass slides were employed in sterilized artificial river water at $\mathrm{pH} 7.0 \pm 0.1$. The systems were kept at $25^{\circ} \mathrm{C}$ and no illumination was provided during this experiment to minimize the photolysis of TCS. 


\subsubsection{TCS and degradation products}

Dissolved TCS concentrations were directly analysed by HPLC following the same method as described in paragraph 2.2 .2 by sampling $1 \mathrm{~mL}$ of the solution from each replicate at $0 \mathrm{~h}, 1 \mathrm{~h}, 3 \mathrm{~h}, 6 \mathrm{~h}, 12 \mathrm{~h}, 24 \mathrm{~h}, 48 \mathrm{~h}, 72 \mathrm{~h}, 96 \mathrm{~h}$, and $120 \mathrm{~h}$.

At the end of degradation experiment $(120 \mathrm{~h}), 100 \mathrm{~mL}$ of the solution from each replicate was collected for breakdown product analysis. The potential degradation products of TCS were extracted by liquid-liquid extraction (Yang et al., 2011). Briefly, $100 \mathrm{~mL}$ of the solution was collected from each replicate, the $\mathrm{pH}$ value was adjusted to about 2 using $2 \mathrm{M}$ $\mathrm{HCl}$, and subsequently $\mathrm{NaCl}$ was added until the solution was saturated. Then the solution was mixed with $3 \times 10 \mathrm{~mL}$ dichloromethane (DCM, HPLC grade, Merck, Shanghai, China) by vigorous shaking. The DCM containing extract was passed through an anhydrous $\mathrm{Na}_{2} \mathrm{SO}_{4}$ column (1 g, CNW Technologies, Dusseldorf, Germany) to remove water. Then the DCM was evaporated under a gentle nitrogen stream and the extract was re-dissolved in $1 \mathrm{~mL}$ of methanol. Each final extract was then filtered through a $0.22 \mathrm{~m}$ nylon syringe filter (Shanghai ANPEL, China) into a $2 \mathrm{~mL}$ amber glass vial which was kept at $-20{ }^{\circ} \mathrm{C}$ until analysis.

The degradation products were detected by a gas chromatography-mass spectrometer (GC-MS), which was an Agilent 6890N gas chromatograph (Agilent, USA) connected to an Agilent 5975B MSD mass spectrometer with a DB-5MS capillary column $(30 \mathrm{~m} \times 0.25 \mathrm{~mm}$, $0.25 \mathrm{~m}$ film thickness) (J\&W, USA). The GC conditions were given as follows: a sample volume of $5 \mu \mathrm{L}$ injected in the splitless mode at $250{ }^{\circ} \mathrm{C}$, the oven temperature programmed from $50{ }^{\circ} \mathrm{C}(5 \mathrm{~min})$ to $300{ }^{\circ} \mathrm{C}$ at $8{ }^{\circ} \mathrm{C} / \mathrm{min}$ followed by a $5 \mathrm{~min}$ hold at $280{ }^{\circ} \mathrm{C}$, and helium used as the carrier gas at a flow rate of $1.0 \mathrm{~mL} / \mathrm{min}$. Mass spectrometer was operated under electron ionization mode at $70 \mathrm{eV}$ with a mass scan range of 40-500 amu. The temperatures of the ion source and interface were $250{ }^{\circ} \mathrm{C}$ and $300^{\circ} \mathrm{C}$, respectively.

\subsubsection{Statistical analyses on degradation efficiencies}

The degradation rates of TCS were calculated in SPSS 16.0 based on the first-order dynamic equation:

$\operatorname{Pr}=a^{*} e^{(-k t)}$

Where $\operatorname{Pr}$ stands for the proportion of residual TCS to corresponding initial concentration, $t$ means the time after starting the removal experiment (h), $k$ is degradation rate, and $a$ is a constant.

In addition, the half-life $\left(\mathrm{T}_{1 / 2}\right)$ of TCS was derived out according to the equation:

$\mathrm{T}_{1 / 2}=(\ln 2) / k$

The dissolved TCS concentrations were natural logarithmic transformed before 
254 performing Williams tests (see paragraph 2.2.5). Since we were interested in the influence of $\mathrm{pH}$ on TCS degradation, the lowest $\mathrm{pH}$ treatment $(\mathrm{pH}=6.5)$ was used as reference.

\section{Results}

\subsection{Effects of TCS on river biofilms}

\subsubsection{Biofilm growth}

260

The biofilms had a total biomass of $64.8 \mu \mathrm{g}$ DW $/ \mathrm{cm}^{2}$ and a chlorophyll-a content of $1.26 \mu \mathrm{g} \mathrm{C}_{\mathrm{A}} / \mathrm{cm}^{2}$ at the beginning of the exposure (Day 0). During the renewal interval of $48 \mathrm{~h}$ in the exposure period, the dissolved TCS concentrations in the treatments decreased from 0.1 to not detected, from 1 to $0.068 \mu \mathrm{g} / \mathrm{L}$, from 10 to $1.26 \mu \mathrm{g} / \mathrm{L}$, from 100 to $11.6 \mu \mathrm{g} / \mathrm{L}$, respectively (Table S1). After the 14-day exposure, the biomass and chlorophyll-a of the biofilms increased in all treatments including the control (Figure 1). The Williams test results show that only the $100 \mu \mathrm{g} / \mathrm{L}$ of TCS treatment significantly inhibited biofilm growth compared to the remaining treatments in terms of total biomass $\left(252 \mu \mathrm{g} \mathrm{DW} / \mathrm{cm}^{2}\right.$ versus $424-$ $\left.578 \mu \mathrm{g} \mathrm{DW} / \mathrm{cm}^{2}\right)$ and chlorophyll-a contents $\left(3.02 \mu \mathrm{g} / \mathrm{cm}^{2}\right.$ versus $\left.5.18-5.42 \mu \mathrm{g} / \mathrm{cm}^{2}\right)$. After the 7-day recovery period, biofilms in all treatments increased 1.24-1.99 times in total biomass and 1.75-2.53 times in chlorophyll-a content compared to the levels at the end of the exposure. But a significant effect was still indicated for the highest treatment level, so no complete recovery took place (Table S2). On the contrary, the calculated chlorophyll-a to dry weight ratios showed no significant differences among all treatments compared to the control during the whole experiment period (Figure $1 \&$ Table S2).

\subsubsection{Molecular analyses}

Before exposure to TCS, the predominant sequences in the detected prokaryotic communities were those representing the phyla Proteobacteria (69\%), Planctomycetes $(6.3 \%)$ and Cyanobacteria (4.4\%). Figure 2A shows that exposure to a high dose of TCS for 14 days caused an higher increase in the relative abundance of the 10 most abundant families in the two highest treatments ( $70 \%$ in $10 \mu \mathrm{g} / \mathrm{L} \mathrm{TCS}$ and $72 \%$ in $100 \mu \mathrm{g} / \mathrm{L} \mathrm{TCS}$ ) compared to the control (63\%), resulting in a decreased species diversity. Methylophilaceae and Rhodospirillales became relatively abundant after exposure in all TCS treatments, as well as exposure to $100 \mu \mathrm{g} / \mathrm{L}$ TCS significantly increased the relative abundance of Xanthomonadaceae and Sphingomonadaceae and decreased the relative abundance of Xanthobacteraceae. After the recovery period, the most abundant 10 families still had a larger proportion of the relative abundance in the TCS treatments compared to the control (54-60\% versus $48 \%$ ), although all the biofilm communities had recovered to a certain extent (Figure 2A). In particular, after this period, the relative abundances of Comamonadaceae, 
while Planctomycetaceae and Chloroplast increased their relative abundance in all the TCS treatments. It is notable that there was a large increase of Xanthomonadaceae in the $100 \mu \mathrm{g} / \mathrm{L}$ TCS treatment (9.7\%) compared to the other treatments and the control (0.36-0.49\%).

During the 14-day exposure, the predominant sequences of Chloroplastida and Eukaryota were, to a certain extent, replaced by Fungi and Metazoa, reflected by the reduced relative abundances of Chlorophyceae and Spirotrichea and the increased ones of Nectriacea and Adinetida (Figure 2B). In addition, the relative abundances of Haplotaxida and Eustigmatales increased significantly in all the TCS treatments compared to the control $(P<$ 0.05). After the 7-day recovery period, the relative abundance of Chloroplastida increased, while Fungi and Metazoa disappeared in all the treatments including the control (Figure 2B). The relative abundances of Eustigmatales were still significantly higher in the TCS treatments compared to the control after the recovery period $(P<0.05)$.

Using the time series of the control groups as reference, PRC analyses were carried out based on the relative abundances at the species level (Figure 3A). Of all variance, 33\% could be attributed to sampling date, which is displayed on the horizontal axis. $30 \%$ of all variance could be explained by the exposure levels, $52 \%$ of which is displayed in the PRC $(P=0.04)$. The results of Monte Carlo permutation tests show that 14-day exposure to TCS resulted in significant changes of the species composition for all treatment levels, while only the biofilm exposed to TCS at $0.1 \mu \mathrm{g} / \mathrm{L}$ recovered afterwards (Table 1 ). However, since in the PRC, Methylotenera sp. and 'Others' exhibited extremely opposite response compared to the other taxa (Figure 3A), the dataset was reanalysed after excluding Methylotenera sp. and 'Others' to optimally show the response of the other taxa as well (Figure 3B). Of all variance, 15\% could be attributed to sampling date. $40 \%$ of all variance could be explained by the exposure levels, $55 \%$ of which is displayed in the PRC $(P=0.002)$. It can be seen that 14 -day exposure resulted in a large shift of the community composition, especially in the high TCS treatments ( 10 and $100 \mu \mathrm{g} / \mathrm{L}$ ), as revealed by the high relative abundances for the phyla of Proteobacteria (e.g., alpha_BAC233, Sphingomonas wittichii, Pseudoxanthomonas mexicana and Sphingopyxis alaskensis), Actinobacteria (e.g., Aciditerrimonas sp., Sporichthya sp. and bacterium_rJ7), and Bacteroidetes (e.g. Niastella sp.), as well as the low relative abundances of the phylum of Actinobacteria (e.g. Gaiella sp.), Planctomycetes (e.g. Gemmata sp. and clone_B55.2011) and some other species of Proteobacteria (e.g. Methyloversatilis universalis, Ralstonia pickettii, Caulobacter sp., Legionella sp.). After the $7 \mathrm{~d}$ recovery period in uncontaminated water, the differences of bacterial community composition with the control were smaller in river biofilms exposed to 10 and $100 \mu \mathrm{g} / \mathrm{L}$ TCS (Figure 3B).

The results of PRC and Monte Carlo permutation tests on eukaryotic data showed that the TCS treatments did not explain a significant part of the variation in eukaryotic community composition $(P>0.05)$. 


\subsection{Degradation of TCS by river biofilms}

The initial TCS concentrations in the treatments were: $100 \mu \mathrm{g} / \mathrm{L}$ (sterilized control), 92 $\mu \mathrm{g} / \mathrm{L}$ (pH6.5), $92 \mu \mathrm{g} / \mathrm{L}$ (pH7.0), $94 \mu \mathrm{g} / \mathrm{L}$ (pH7.5), $93 \mu \mathrm{g} / \mathrm{L}$ (pH8.0) and $101 \mu \mathrm{g} / \mathrm{L}(\mathrm{pH} 8.5$ ). Figure 4 shows that the TCS concentration was constant in the sterilized control, implying that no other degradation processes than microbial degradation was of importance during the whole experiment. At $120 \mathrm{~h}$, the residual dissolved TCS in each $\mathrm{pH}$ treatments were reduced to 36 to $60 \%$, showing a stronger removal efficiency at higher $\mathrm{pH}$ values.

The half-life of TCS at pH8.5 was calculated as $3.7 \mathrm{~d}$ (Table 2), reflecting the relatively high degradation or dissipation efficiency of TCS by river biofilm at pH8.5 when compared to those of the other lower $\mathrm{pH}$ treatments (5.1-7.8 d). This is confirmed by the Williams test which calculated a NOEC value of $\mathrm{pH}$ of 8.0 at the $120 \mathrm{~h}$ time point (Table 3 ).

Degradation products of TCS were not detected in the artificial river water used in the TCS removal experiment.

\section{Discussion}

\subsection{Effects of TCS on river biofilms}

TCS blocks bacterial lipid synthesis through specific inhibition of the NADHdependent enzyme ENR (enoyl-acyl carrier protein reductase) (Adolfsson-Erici et al., 2002), and affects algae primarily by inhibiting fatty acid synthesis and causing protein aggregation (Xin et al. 2017). Furthermore, Escalada et al. (2005) summarized that low TCS concentrations (20-500 $\mu \mathrm{g} / \mathrm{L})$ affected the growth of several bacteria, while several microalgae were reported with sensitivities (EC50) between 0.7 and $19.1 \mu \mathrm{g} / \mathrm{L}$, making them the most susceptible group compared to activated-sludge microorganisms, invertebrates and fish, based on single species studies (Orvos, 2002; Tatarazako, 2004). This was confirmed by Lawrence et al. (2015) who showed that exposure to $1.8 \mu \mathrm{g} / \mathrm{L}$ TCS resulted in significant reductions in algal and cyanobacterial biomass but no significant effects were observed on bacterial biomass in river biofilms cultivated in rotating annular reactors. At 0.1 to $0.5 \mu \mathrm{g} / \mathrm{L}$, TCS even stimulated the stream biofilm with increased bacteria cell densities, but higher doses $(5 \mu \mathrm{g} / \mathrm{L}$ and $10 \mu \mathrm{g} / \mathrm{L})$ significantly decreased bacterial cell densities and cyanobacteria abundance (Nietch et al. 2013). Compared to reductions in algal biomass observed in continuous exposure to TCS, the absence of significant effects of TCS at low levels $(\leq 10$ $\mu \mathrm{g} / \mathrm{L}$ ) in the present study (Figure 1) might be explained by the reduced actual concentrations of TCS resulting from the periodic dosing and degradation process of TCS between renewal intervals. Table S1 shows that after 2 days of exposure only $5-14 \%$ of the initial dose is left in the water phase, making the time weighted average concentrations lower that the nominal concentrations, but our characterisation of the exposure dynamics is too coarse to be able to 
calculate the time weighted average concentrations. At the same time, this is also the possible reason why both algal biomass and the total biomass of river biofilm decreased only by exposure to $100 \mu \mathrm{g} / \mathrm{L}$ TCS in the present study.

Moreover, derived from the changes of total biomass and chlorophyll-a content during the recovery period, the biofilm exposed to $100 \mu \mathrm{g} / \mathrm{L}$ TCS showed similar growth rates as the other treatments and control, implying that the low level of biomass after the exposure period is the cause for the lack of recovery in the $100 \mu \mathrm{g} / \mathrm{L}$ TCS treatment (Figure 1)

Molecular analyses provide detailed information on the shift of microbial community composition initiated by environmental stressors. As shown in Figure 3, exposure to TCS levels significantly altered the bacterial community composition of river biofilm. For instance, Figure 3A shows that the relative abundance of Methylotenera sp. increased significantly in all treatment levels with a decreasing relative abundance of "Others", indicating the negative influence of TCS on biofilm biodiversity. Besides, Methylotenera sp. are obligatory or restricted facultative methylamine-utilizing bacteria within the family Methylophilaceae (Figure 2A) (Kalyuzhnaya et al., 2012; Paul et al., 2015) and played a key role in microbial degradation of water pollutants (Yang et al., 2018). In the present study, the increased relative abundance of Methylotenera sp. implied its function in the biodegradation of TCS. Furthermore, P. mexicana belonging to $\gamma$-Proteobacteria, S. alaskensis and $S$. wittichii belonging to $\alpha$-Proteobacteria, significantly increased their relative abundance resulting from exposure to higher concentrations ( $10 \mu \mathrm{g} / \mathrm{L}$ and $100 \mu \mathrm{g} / \mathrm{L}$ ) of TCS (Figure 3B). Lubarsky et al. (2012) also reported that some species in $\gamma$-Proteobacteria appeared insensitive to TCS at 2-100 $\mu \mathrm{g} / \mathrm{L}$. Niculae et al. (2016) observed that a strain of P. mexicana degraded aromatic and aliphatic hydrocarbons in different environments.. In addition, several studies confirmed that $S$. alaskensis and $S$. wittichii own the ability to utilize a wide range of organic compounds (Godoy et al., 2003; Nishiyama et al., 1992). Thus TCS and its degradation products, as aromatic compounds, might be utilized by these species as a source of carbon for growth, subsequently leading to the increase of their relative abundance in the present study. To the contrary, two species in $\beta$-Proteobacteria, $R$. pickettii and $M$. universalis, were inhibited by $10-100 \mu \mathrm{g} / \mathrm{L}$ TCS (Figure 3B). The decreased relative abundance of $\beta$-Proteobacteria was observed previously in cultivated river biofilm exposed to 2-100 $\mu \mathrm{g} / \mathrm{L}$ TCS (Lubarsky et al., 2012) and in sediment spiked with $12 \mathrm{mg} / \mathrm{kg}$ TCS (Drury et al., 2013), indicating they are species sensitive to TCS.

The lack of recovery of the river biofilm during the post-exposure period was previously observed under different experimental designs. For instance, Proia et al. (2011) showed that TCS strongly inhibited phosphate uptake (-71\%), which did not return to normal values until 2 weeks post-exposure. Lawrence et al. (2015) found that the biomass component patterns of bacteria, cyanobacteria and algae in river biofilms still presented significant differences between the treatments after 2-6 weeks of recovery and the control. In 
401

the present study, the growth of biofilm exposed to $100 \mu \mathrm{g} / \mathrm{L}$ TCS was still significantly inhibited compared to the control after the 7-day recovery period (Figure 1). Meanwhile, it can be seen from Figure $3 \mathrm{~B}$ that the bacterial species composition of biofilms exposed to 10$100 \mu \mathrm{g} / \mathrm{L}$ TCS did not completely return to the control level. The adsorbed TCS might have prevented the recovery as hydrophobic aromatic compound, like TCS, partitions into organic matter, such as extracellular polymeric substances (Branda et al., 2005). Although the dissolved TCS in artificial river water was removed, adsorbed TCS would remain in the river biofilm and continued to affect the microorganisms in the biofilm.

In the present study, PRC analyses indicated that exposure to TCS in the range of 0.1 $100 \mu \mathrm{g} / \mathrm{L}$ did not show significant effect on eukaryotic community composition of river biofilms, which is consistent with the findings that the exposure to $1.4-2621 \mu \mathrm{g} / \mathrm{L} \mathrm{TCS}$ affected the total biomass rather than specific pigments (Johansson et al., 2014). However, being the most susceptible taxa to TCS, microalgal species are probably affected through multiple target sites and the differences in sensitivity of microalgae cover three orders of magnitude (Franz et al., 2008). Thus, it is reasonable to deduce that low levels of exposure to TCS may shift the community composition of microalgal systems, as Lawrence et al. (2015) observed significant changes in pigment composition of algal and cyanobacterial populations in river biofilm exposed to $1.8 \mu \mathrm{g} / \mathrm{L}$ TCS. Therefore, the question of whether the community composition of microalgal species in biofilms is affected significantly by TCS needs to be investigated further by more research work.

\subsection{Removal of TCS by river biofilms}

TCS is quite stable against hydrolysis and photolysis is a major removal pathway in natural aquatic environment (Aranami et al., 2007; Lindstrom et al., 2002; Tixer et al., 2002). In the toxicity experiment of the present study, more than $88 \%$ of the initial TCS in the artificial river water was eliminated within $48 \mathrm{~h}$ under illumination. In the following experiment, illumination was shielded and the removal efficiency of TCS by river biofilms was $36 \%$ to $60 \%$ at a series of $\mathrm{pH}$ levels within $120 \mathrm{~h}$, indicating that the photolysis process of TCS was effectively minimized. The half-life of TCS was $3.7 \mathrm{~d}$ to $7.8 \mathrm{~d}$ in the present degradation study, which was relatively fast compared to the half-life of $18 \mathrm{~d}$ for the biodegradation of TCS in aerobic soil (Ying et al., 2007). This could be explained by relatively high relative abundance of TCS-degrading bacteria detected in the present study, such as S. alaskensis and S. wittichii, (Figure 3). A similar finding was reported by Chen et al. (2011) who found that in a laboratory-scale activated sludge reactor, $75 \%$ of the TCS was removed under aerobic conditions within $150 \mathrm{~h}$. Meanwhile, a much higher removal rate of $96 \%$ in 5 days using an exposure concentration of $10 \mathrm{mg} / \mathrm{L}$, was previously reported (Gangadharan Puthiya Veetil et al., 2012) when using isolated batch cultures of TCS tolerant bacterial strains. 
In this removal experiment, biodegradation and adsorption might be the main processes which removed TCS from the liquid phase. TCS deprotonates to its negatively ionic phenolate form at $\mathrm{pH}>8.1$ (Nietch et al., 2013). Therefore, the higher fraction of neutral TCS was present in the lower $\mathrm{pH}$ conditions of this removal experiment. Because of its hydrophilic characteristic, neutral TCS tends to adsorb to river biofilms which contain organic carbon. However, it was observed that the lower $\mathrm{pH}$ conditions resulted in lower removal efficiency of TCS, implying that adsorption was not so important for the removal of TCS from the water phase in the present study. Hence, we deduce that the biodegradation by river biofilms might play the vital role. As the $\mathrm{pH}$ levels increased from 6.5 to 8.5 , the ionized form of TCS replaced the neutral form which is responsible for the majority of TCS's toxic effects (Orvos, 2002). Thus, at higher pH levels, TCS had a lower toxic effect on communities to degrade TCS.

In the present study, the bacterial species in the river biofilm communities were most important for the biodegradation of TCS. The results of toxicity experiment indicate that bacterial species, such as $P$. mexicana, $S$. alaskensis and $S$. wittichii, were stimulated by higher concentrations of TCS. Gangadharan Puthiya Veetil et al. (2012) isolated 3 bacterial strains which were tolerant to TCS up to $1 \mathrm{~g} / \mathrm{L}$ and able to degrade $95 \%$ of TCS in 5 days, which were identified as Pseudomonas sp. Mulla et al. (2016) confirmed the biodegradation of TCS by Sphingomonas sp. which was able to catabolize TCS to intermediates with a lower toxicity. Sphingopyxis strain KCY1 is capable of dechlorinating TCS with a stoichiometric release of chloride (Lee et al., 2012). In the present study, these bacterial species survived during exposure to high dose of TCS, utilized or catabolised TCS, and increased their abundance (Figure 3). By contrast, as discussed above, the high concentration of TCS exceeded the tolerance level of most fresh-water algae. Meanwhile, little information is currently available on the degradation potential of algal species for TCS. We may conclude that in this experiment, the algal species in the river biofilm were not able to degrade TCS. On the other hand, based on TCS bioaccumulation factor (BAF) value of 1600 in algal species (Coogan et al., 2007), the adsorption process to algal community in river biofilms might also contribute to the removal of TCS.

Ionized TCS may be degraded by direct environmental photolysis into 2,8dichlorodibenzo-p-dioxin (2,8-DCDD) and 2,4-dichlorophenol (2,4-DCP) (Latch et al., 2005). However, the photolysis process of TCS was eliminated during our removal experiment. Thus, no 2,4-DCP and 2,8-DCDD could be detected in the river water phase. In addition, methyl-triclosan (Me-TCS) is a metabolite of TCS (Coogan et al., 2007). It has been detected in active sludge (Chen et al., 2011), biosolids-amended soil (Waria et al., 2011) and cultures of certain bacteria in laboratory (Lee et al., 2013). Nevertheless, Me-TCS is more lipophilic and environmentally persistent than the parent compound (Coogan et al., 
2007). Therefore, in our removal experiment, most of the degradation products probably partitioned in the river biofilms. Besides, Chen et al. (2011) found that only $1 \%$ of TCS was catalyzed to be Me-TCS with a TCS removal rate of $75 \%$ in active sludge. In our removal experiment, it can be deduced that less TCS was transformed to Me-TCS under a relatively low removal efficiency. Thus it should be a better option to detect the degradation products adsorbed by river biofilm instead of those dissolved in the artificial river water. Another reason for the lack of detection of degradation products in our study might be the existence of bacterial species which can utilize organic compounds for growth, such as Methylotenera sp., Methyloversalitis universalis and Methylobacterium aquaticum (Figure 3). They are methylotrophic bacteria which are capable of utilizing single carbon compounds as sole sources of carbon and energy (Kittichotirat et al., 2011; Vuilleumier et al., 2009).

\section{Conclusions}

The results from this study showed significant inhibition of river biofilm at the high dose treatment by $100 \mu \mathrm{g} / \mathrm{L}$ TCS. The incubation material was collected from a subtropical river in Guangdong Province, so a subtropical community has been tested. Besides, although the lab conditions are not typically subtropical, we can find similar temperatures for subtropical rivers in the research area in March, April, October and November. Exposure to TCS from 0.1 to $100 \mu \mathrm{g} / \mathrm{L}$ resulted in the shift of the taxonomic composition of river biofilms especially in terms of bacteria species. The inhibited biofilm could not completely recover within $7 \mathrm{~d}$ of no TCS exposure. Besides, river biofilm could efficiently remove TCS from the aqueous phase through biodegradation and adsorption. Our findings indicate that TCS may pose risks on river ecosystems, and the adaptation of biofilm community to exposure may promote its resistance and removal ability to TCS. Further research is needed to understand the cause of TCS degradation in the system.

\section{Acknowledgements}

The authors would like to acknowledge the partial support from National Natural Science Foundation of China (U1701242 and 41473105).

\section{References}

Adolfsson-Erici, M., Pettersson, M., Parkkonen, J., Sturve, J., 2002. Triclosan, a commonly used bactericide found in human milk and in the aquatic environment in Sweden. Chemosphere 46, 1485-1489.

Aranami, K., Readman, J.W., 2007. Photolytic degradation of triclosan in freshwater and 
seawater. Chemosphere, 66(6), 1052-1056.

Branda, S.S., Vik, S., Friedman, L., Kolter, R., 2005. Biofilms: the matrix revisited. Trends in Microbiology 13 (1), 20-26.

Bechtold, H.A., Marcarelli, A.M., Baxter, C.V., Inouye, R.S., 2012. Effects of N, P, and organic carbon on stream biofilm nutrient limitation and uptake in a semi-arid watershed. Limnology and Oceanography 57 (5), 1544-1554.

Chen, X., Nielsen, J.L., Furgal, K., Liu, Y., Lolas, I.B., Bester, K., 2011. Degradation of Triclosan and formation of metabolites in aerobic activated sludge. Chemosphere 84(4), 452-456.

Coogan, M.A., Edziyie, R.E., La Point, T.W., Venables, B.J., 2007. Algal bioaccumulation of triclocarban, triclosan, and methyl-triclosan in a North Texas wastewater, treatment plant receiving stream. Chemosphere 67(10), 1911-1918.

Dellaporta, S.L., Wood, T., Hicks, T.B., 1983. A plant DNA mini preparation: version II. Plant Molecular Biology Reporter 1, 19-21.

Drury, B, Scott, J, Rosi-Marshall, E.J, Kelly, J.J., 2013. Triclosan exposure increases triclosan resistance and influences taxonomic composition of benthic bacterial communities. Environmental Science and Technology 47(15), 8923-8930.

Edgar, R.C., 2004. MUSCLE: multiple sequence alignment with high accuracy and high throughput. Nucleic acids research 32(5), 1792-1797.

Edgar, R.C., 2013. UPARSE: highly accurate OTU sequences from microbial amplicon reads. Nature methods 10(10), 996-998.

Escalada, M.G., Russell, A.D., Maillard, J.Y., Ochs, D., 2005. Triclosan-bacteria interactions: single or multiple target sites? Letters in Applied Microbiology 41, 476-481.

Franz, S., Altenburger, R., Heilmeier, H., Schmitt-Janse, M., 2008. What contributes to the sensitivity of microalgae to triclosan? Aquatic Toxicology 90, 102-108.

Gangadharan Puthiya Veetil, P., Vijaya Nadaraja, A., Bhasi, A., Khan, S., Bhaskaran, K., 2012. Degradation of triclosan under aerobic, anoxic, and anaerobic conditions. Applied Biochemistry and Biotechnology 167(6), 1603-12.

Godoy, F., Vancanneyt, M., Martinez, M., Steinbuchel, A., Swings, J., Rehm, B.H.A., 2003. Sphingopyxis chilensis sp. nov., a chlorophenol-degrading bacterium that accumulates polyhydroxyalkanoate, and transfer of Sphingomonas alaskensis to Sphingopyxis alaskensis comb. nov. International Journal of Systematic and Evolutionary Microbiology 53, 473-477.

Hall-Stoodley, L., Costerton, J.W., Stoodley P., 2004. Bacterial biofilms: from the natural 
environment to infectious diseases. Nature Reviews. Microbiology 2 (2), 95-108.

Hommen, U., Düllmer, U., Vith, D., 1994. A computer program to evaluate plankton data from freshwater field tests, in: Hill, I.R., Heimbach, F., Leeuwangh, P., Matthiesen, P. (Eds.), Freshwater Field Tests for Hazard Assessment of Chemicals. Lewis Publishers, Baca Raton, USA, pp. 503-513.

Huang, X.L., Wu, C.X., Hu, H.J., Yu, Y.H., Liu, J.T., 2015. Sorption and degradation of triclosan in sediments and its effect on microbes. Ecotoxicology and Environmental Safety $116,76-83$.

Huerta, B., Rodriguez-Mozaz, S., Nannou, C., Nakis, L., Ruhi, A., Acuna, V., Sabater, S., Barcelo, D., 2016. Determination of a broad spectrum of pharmaceuticals and endocrine disruptors in biofilm from a waste water treatment plant-impacted river. Science of The Total Environment 540, 241-249.

Johansson, C.H., Janmar, L., Backhaus, T., 2014. Triclosan causes toxic effects to algae in marine biofilms, but does not inhibit the metabolic activity of marine biofilm bacteria. Marine Pollution Bulletin 84(1-2), 208-212.

Khatikarn, J., Satapornvanit, K., Price, O.R., Van den Brink, P.J., 2018. Effects of triclosan on aquatic invertebrates in tropics and the influence of $\mathrm{pH}$ on its toxicity on microalgae. Environmental Science and Pollution Research 25, 13244-13253.

Kittichotirat, W., Good, N.M., Hall, R., Bringel, F., Lajus, A., Médigue, C., Smalley, N.E., Beck, D., Bumgarner, R., Vuilleumier, S., Kalyuzhnaya, M.G., 2011. Genome sequence of Methyloversatilis universalis FAM5T, a methylotrophic representative of the order Rhodocyclales. Journal of Bacteriology 193(17), 4541-4542.

Latch, D.E., Packer, J.L., Stender, B.L., VanOverbek, J., Arnold, W.A., McNeill, K., 2005. Aqueous photochemistry of triclosan: formation of 2,4-dichlorophenol, 2,8 dichlorodibenzo-pdioxin, and oligomerization products. Environmental Science and Technology 24(3), 517-525.

Lawrence, J.R., Zhu, B., Swerhone, G.D.W., Roy, J., Wassenaar, L.I., Topp, E., Korber, D.R., 2009. Comparative microscale analysis of the effects of triclosan and triclocarban on the structure and function of river biofilm communities. Science of The Total Environment 407, 3307-3316.

Lawrence, J.R., Topp, E., Waiser, M.J., Tumber, V., Roy, J., Swerhone, G.D., Leavitt, P., Paule, A., Korber, D.R.. 2015. Resilience and recovery: the effect of triclosan exposure timing during development, on the structure and function of river biofilm communities. Aquatic Toxicology 161, 253-266.

Lee, D.G., Zhao, F., Rezenom, Y.H., Russell, D.H., Chu, K.H., 2012. Biodegradation of 
triclosan by a wastewater microorganism. Water Research 46(13), 4226-4234.

600 601
Lehutso, R.F., Daso, A.P., Okonkwo, J.O., 2017. Occurrence and environmental levels of triclosan and triclocarban in selected wastewater treatment plants in Gauteng Province, South Africa. Emerging Contaminants 3(3), 107-114.

Lindstrom, A., Buerge, I.J., Poiger, T., Bergqvist, P.A., Muller, M.D., Buser, H.R., 2002. Occurrence and environmental behavior of the bactericide triclosan and its methyl derivative in surface waters and in wastewater. Environmental Science and Technology 36(11), 2322-2329.

Lubarsky, H.V., Gerbersdorf, S.U., Hubas, C., Behrens, S., Ricciardi, F., Paterson, D.M., 2012. Impairment of the bacterial biofilm stability by triclosan. PLoS One 7(4), e31183.

Meyer, R.D., 1983. Legionella infections: a review of five years of research. Reviews of infectious diseases 5, 258-278.

Miranda, A.R.L., Antunes, J.E.L., Araujo, F.F., Melo, V.M.M., Bezerra, W.M., Van den Brink, P.J., Araujo, A.S.F., 2018. Less abundant bacterial groups are more affected than those most abundant in composted tannery sludge treated soil. Scientific Reports 8, 11755 .

Mueller, S.R., Singer, H.P., Canonica, S., 2000. Fate and behavior of the biocide triclosan in the aquatic environment. Abstracts of Papers of the American Chemical Society 219, 166-167.

Mulla, S.I., Wang, H., Sun, Q., Hu, A., Yu, C.P., 2016. Characterization of triclosan metabolism in sphingomonas sp. strain yl-jm2c. Scientific Reports 6(1), 21965.

Niculae, G., Oancea, F., Rusen, R., Doni, M., Raut, I., Calin, M., Jecu, M.L., 2016. Strain of Pseudoxanthomonas mexicana and controlled release composition which contain said strain. European Patent Specification, EP2738267.

Nietch, C.T., Quinlan, E.L., Lazorchak, J.M., Impellitteri, C.A., Raikow, D., Walters, D., 2013. Effects of a chronic lower range of triclosan exposure on a stream mesocosm community. Environmental Toxicology and Chemistry 32, 2874-2887.

Nishiyama, M., Senoo, K., Wada, H., Matsumoto, S., 1992. Identification of soil microhabitats for growth, death and survival of a bacterium, g-1,2,3,4,5,6hexachlorocyclohexane -assimilating Sphingomonas paucimobilis, by fractionation of soil. FEMS Microbiology Ecology 101, 145-150.

Orvos, D.R., Versteeg, D.J., Inauen, J., Capdevielle, M., Rothenstein, A., Cunningham, V., 2002. Aquatic toxicity of triclosan. Environmental Toxicology and Chemistry 21(7), 1338-1349. 
Paul, D., Kazy, S.K., Gupta, A.K., Pal, T., Sar, P., 2015. Diversity, metabolic properties and arsenic mobilization potential of indigenous bacteria in arsenic contaminated groundwater of west bengal, india. PLoS One, 10(3), e0118735.

Peng, F.J., Pan, C.G., Zhang, M., Zhang, N.S., Windfeld, R., Salvito, D., Selck, H., Van den Brink, P.J., Ying, G.G., 2017. Occurrence and ecological risk assessment of emerging organic chemicals in urban rivers: Guangzhou as a case study in China. Science of the Total Environment 589, 46-55.

Peng, F.Q., Ying, G.G., Yang, B., Liu, Y.S., Lai, H.J., Zhou, G.J., Chen, J., Zhao, J.L., 2014. Biotransformation of the flame retardant tetrabromobisphenol-a (Tbbpa) by freshwater microalgae. Environmental Toxicology and Chemistry 33(8), 1705-1711.

Podda, F., Medas, D., De Giudici, G., Ryszka, P., Wolowski, K., Turnau, K., 2014. Zn biomineralization processes and microbial biofilm in a metal-rich stream (Naracauli, Sardinia). Environmental Science and Pollution Research 21(11), 6793-6808.

Proia, L., Cassiò, F., Pascoal, C., Tlili, A., Romaní, A.M., 2012. The use of attached microbial communities to assess ecological risks of pollutants in river ecosystems. The role of heterotrophs. In: Guasch H., Ginebreda A., Geiszinger A., editors. Emerging and priority pollutants in rivers: bringing science into river management plans. Berlin Heidelberg: Springer Verlag, Berlin, Germany; pp. 55-83.

Proia, L., Morin, S., Peipoch, M., Romaní, A.M., Sabater, S., 2011. Resistance and recovery of river biofilms receiving short pulses of triclosan and diuron. Science of The Total Environment 409, 3129-3137.

Roh, H., Subramanya, N., Zhao, F., Yu, C.P., Sandt, J., Chu, K.H., 2009. Biodegradation potential of wastewater micropollutants by ammonia-oxidizing bacteria. Chemosphere 77(8), 1084-1089.

Rosi-Marshall, E.J., Kincaid, D.W., Bechtold, H.A., Royer, T.V., Rojas, M., Kelly, J.J., 2013. Pharmaceuticals suppress algal growth and microbial respiration and alter bacterial communities in stream biofilms. Ecological Applications 23, 583-593.

Saghai-Maroof, M.A., Soliman, K.M., Jorgensen, R.A., Allard, R.W., 1984. Ribosomal DNA spacer-length polymorphisms in barley: mendelian inheritance, chromosomal location, and population dynamics. PNAS 81(24), 8014-8018.

Tatarazako, N., Ishibashi, H., Teshima, K., Kishi, K., \& Arizono, K., 2004. Effects of triclosan on various aquatic organisms. Environmental Science 11(2), 133-140.

Ter Braak, C.J.F., Smilauer, P., 2012. Canoco reference manual and user's guide: software for ordination. Version 5. Microcomputer Power Ithaca, New York, USA.

Van den Brink, P.J., Ter Braak, C.J.F., 1999. Principal response curves: Analysis of time- 

dependent multivariate responses of biolog
Toxicology and Chemistry 18(2), 138-148.

Vuilleumier, S., Chistoserdova, L., Lee, M.C., Bringel, F., Lajus, A., Zhou, Y., Gourion, B., Barbe, V., Chang, J., Cruveiller, S., Dossat, C., Gillett, W., Gruffaz, C., Haugen, E., Hourcade, E., Levy, R., Mangenot, S., Muller, E., Nadalig, T., Pagni, M., Penny, C., Peyraud, R., Robinson, D.G., Roche, D., Rouy, Z., Saenampechek, C., Salvignol, G., Vallenet, D., Wu, Z., Marx, C.J., Vorholt, J.A., Olson, M.V., Kaul, R., Weissenbach, J., Médigue, C., Lidstrom, M.E., 2009. Methylobacterium genome sequences: a reference blueprint to investigate microbial metabolism of $\mathrm{C} 1$ compounds from natural and industrial sources. PLoS One 4(5), e5584.

Wang, Q., Garrity, G.M., Tiedje, J.M., Cole, J.R., 2007. Naive Bayesian classifier for rapid assignment of rRNA sequences into the new bacterial taxonomy. Applied and environmental microbiology 73(16), 5261-5267.

Waria, M., O'Connor, G.A., Toor, G.S., 2011. Biodegradation of triclosan in biosolidsamended soils. Environmental Toxicology and Chemistry 30(11), 2488-2496.

Williams, D.A., 1972. The comparison of several dose levels with a zero-dose control. Biometrics 28(2), 519-531.

Yang, B., Ying, G.G., Zhao, J.L., Zhang, L.J., Fang, Y.X., Nghiem, L.D., 2011. Oxidation of triclosan by ferrate: Reaction kinetics, products identification and toxicity evaluation. Journal of Hazardous Materials 186(1), 227-235.

Yang, H., Yang, X.N., Zhang, G.Z., Wang, B.S., Zhang, X., Li, J., 2018. Key bacteria for the microbial degradation of pollutants in cellar water. Environmental Science 39(10), 4766-4776.

Ying, G.G., Yu, X.Y., Kookana, R. S., 2007. Biological degradation of triclocarban and triclosan in a soil under aerobic and anaerobic conditions and comparison with environmental fate modelling. Environmental Pollution 150(3), 300-305.

Zhang, N.S., Liu, Y.S., Van den Brink, P.J., Price, O.R., Ying, G.G., 2015. Ecological risks of home and personal care products in the riverine environment of a rural region in South China without domestic wastewater treatment facilities. Ecotoxicology and Environmental Safety 122, 417-425.

Zhao, J.L., Ying, G.G., Liu, Y.S., Chen, F., Yang, J. F., Wang, L., 2010. Occurrence and risks of triclosan and triclocarban in the Pearl River system, South China: From source to the receiving environment. Journal of Hazardous Materials 179(1-3), 215-222. 
683 Table $1 P$ values derived from Monte Carlo permutation tests on the differences of prokaryotic 684 community composition between each treatment and the control. T01, T1, T10 and T100 stand 685 for the treatments exposed to triclosan at $0.1 \mu \mathrm{g} / \mathrm{L}, 1 \mu \mathrm{g} / \mathrm{L}, 10 \mu \mathrm{g} / \mathrm{L}$ and $100 \mu \mathrm{g} / \mathrm{L}$, respectively.

\begin{tabular}{ccccc}
\hline & T01 & T1 & T10 & T100 \\
\hline Day 14 & 0.02 & 0.02 & 0.02 & 0.05 \\
Day 21 & 0.14 & 0.02 & 0.02 & 0.02 \\
\hline
\end{tabular}

686 
687 Table 2 The first-order removal parameters and the resulting half-life of triclosan by river 688 biofilms at different $\mathrm{pH}$ values

\begin{tabular}{ccccc}
\hline Treatment & $\mathrm{a}$ & $k\left(\mathrm{~d}^{-1}\right)$ & $T_{I / 2}(d)$ & $\mathrm{R}^{2}$ \\
\hline $\mathrm{pH} 6.5$ & 0.9690 & 0.0890 & 7.788 & 0.9430 \\
$\mathrm{pH} 7.0$ & 0.9475 & 0.1159 & 6.796 & 0.8941 \\
$\mathrm{pH} 7.5$ & 0.9585 & 0.1020 & 5.981 & 0.8849 \\
$\mathrm{pH} 8.0$ & 0.9666 & 0.1358 & 5.104 & 0.8972 \\
$\mathrm{pH} 8.5$ & 0.9544 & 0.1867 & 3.713 & 0.8495 \\
\hline
\end{tabular}

689 
690 Table 3 NOECs derived from Williams test for the residual of triclosan (\%) at a series of $\mathrm{pH}$ 691 levels

692

\begin{tabular}{ccccccc}
\hline Time & pH6.5 & pH7.0 & pH7.5 & pH8.0 & pH8.5 & NOEC \\
\hline $24 \mathrm{~h}$ & 85.5 & 83.3 & 77.5 & 80.7 & 77.6 & $\mathrm{pH} 8.5$ \\
$72 \mathrm{~h}$ & 76.4 & 71.2 & 69.5 & 69.3 & 61.3 & $\mathrm{pH} 8.0$ \\
$120 \mathrm{~h}$ & 60.0 & 57.4 & 52.0 & 46.6 & 35.8 & $\mathrm{pH} 8.0$ \\
\hline
\end{tabular}

693

${ }^{a}$ Treatment at pH6.5 was taken as control in Williams test 

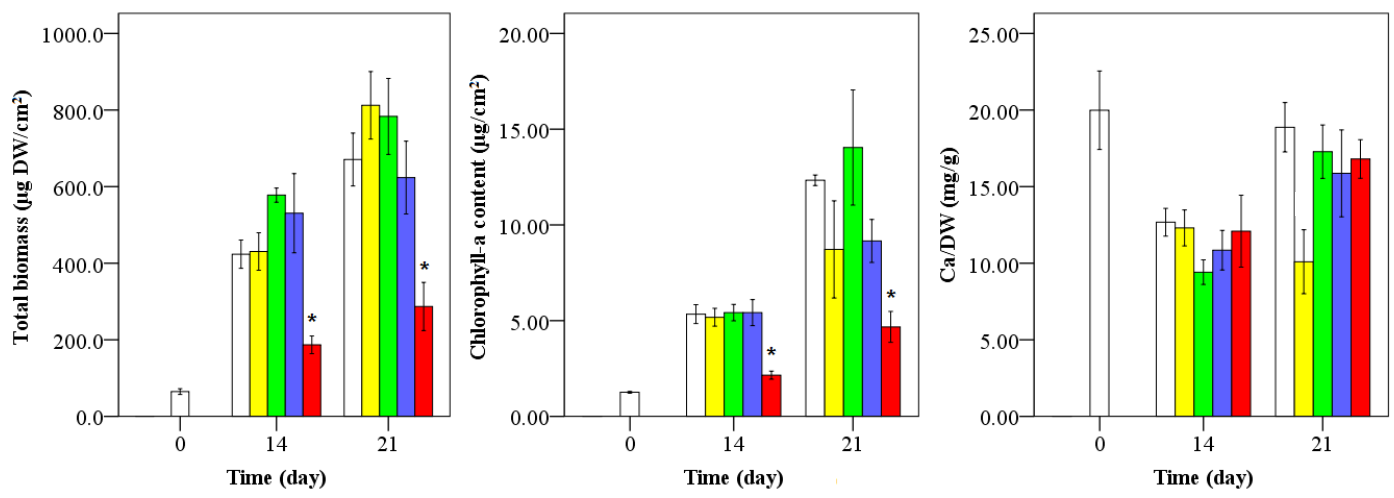

694

695 Figure 1 Effects of triclosan on the growth of river biofilms in terms of dry weight (DW),

696 chlorophyll-a $\left(\mathrm{C}_{\mathrm{A}}\right)$, and $\mathrm{C}_{\mathrm{A}} / \mathrm{DW}$. The error bars indicate standard errors. The asterisk labels the

697 treatment with significant difference $(P<0.05)$ from the corresponding control at each

698 sampling time (day 14 and day 21). 

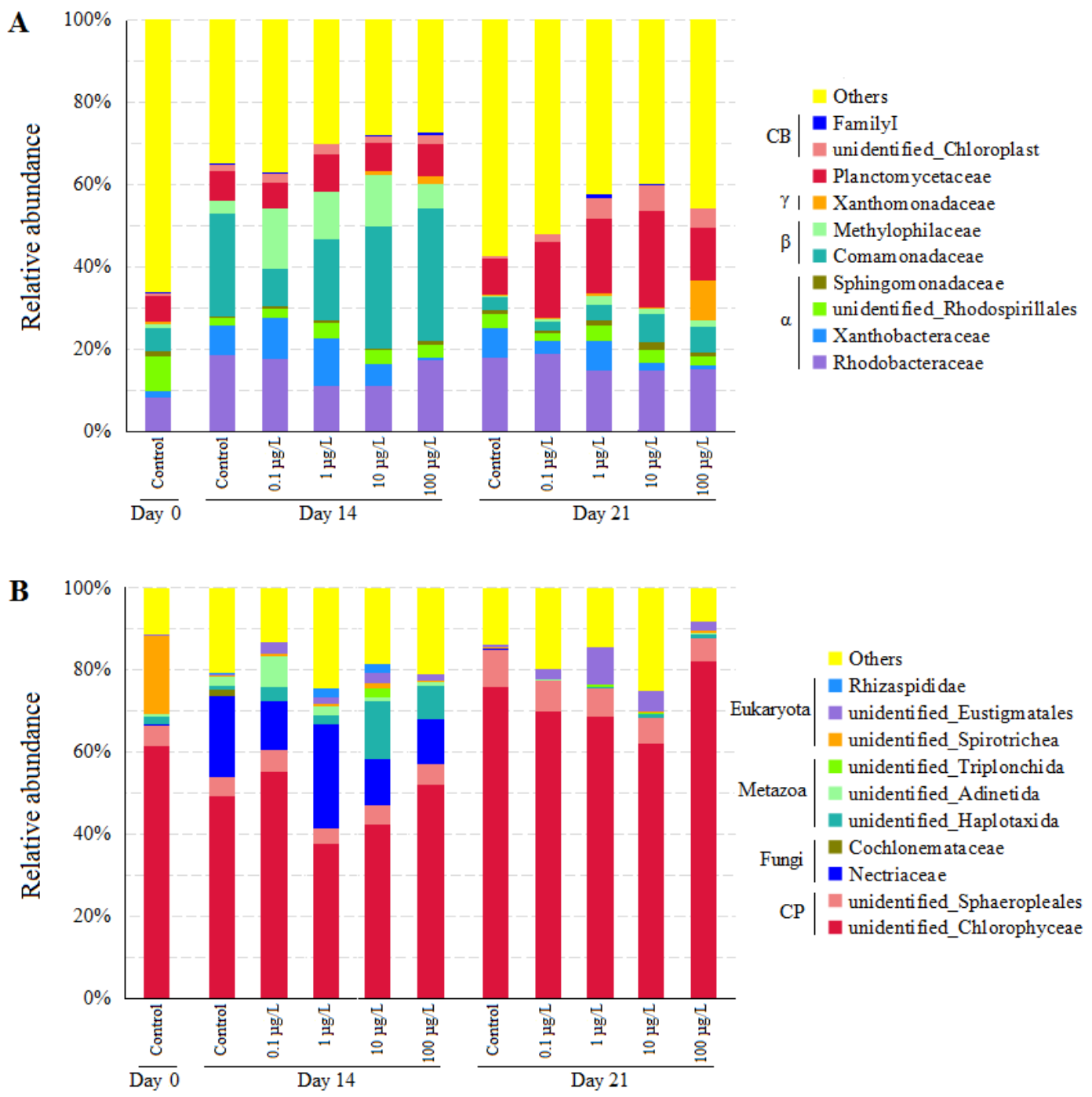

701 Figure 2 Bar charts of family-level relative abundances of prokaryotes (A) and eukaryotes (B)

702 in river biofilms affected by triclosan exposure (Day 14) and recovery (Day 21). $\alpha$, alpha703 Proteobacteria; $\beta$, beta-Proteobacteria; $\gamma$, gamma-Proteobacteria; CB, Cyanobacteria; CP, 704 Chloroplastida (green algae) 

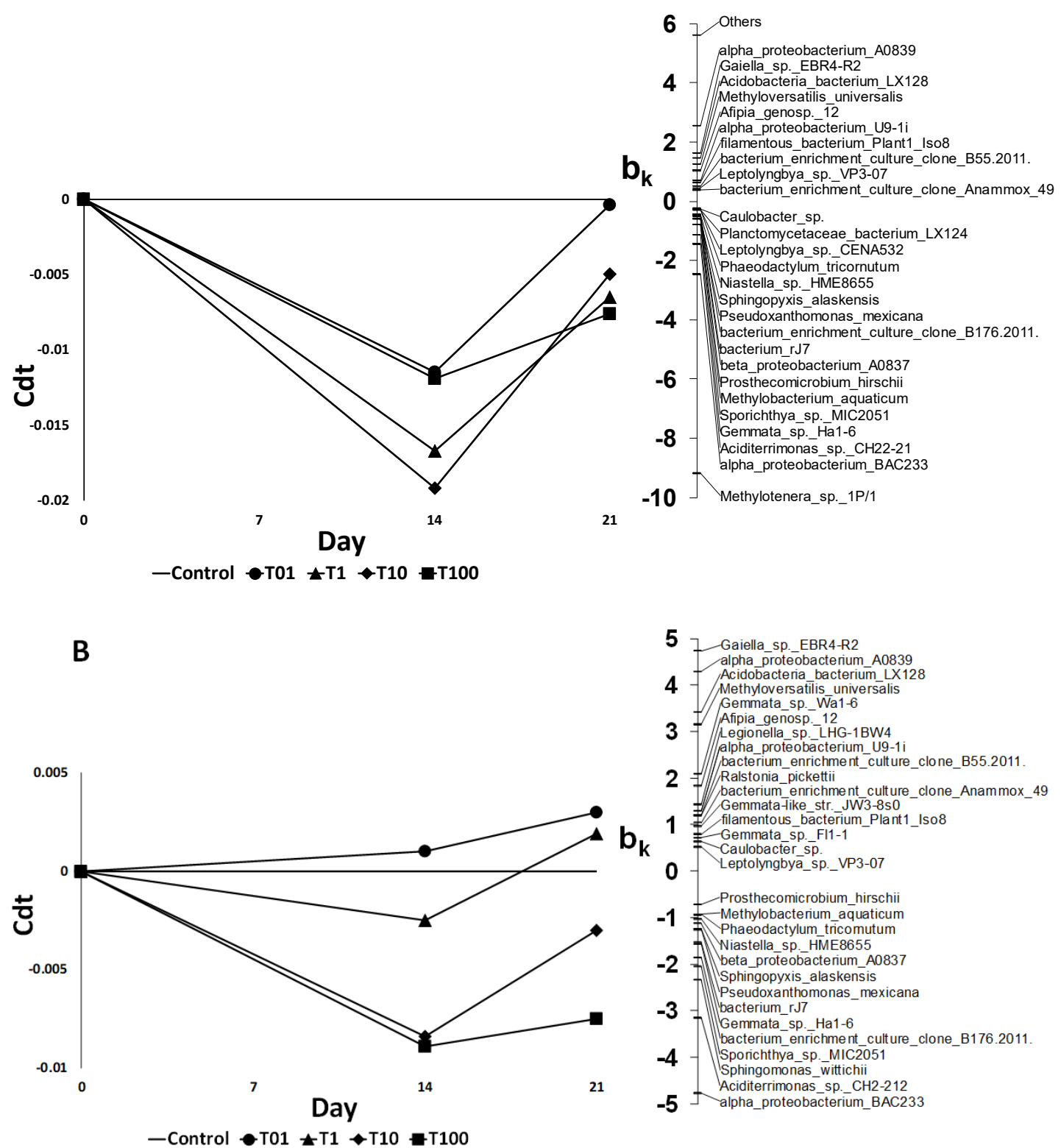

Figure 3. PRC resulting from the analysis of the prokaryotic data set, indicating the effects of 708 TCS on the prokaryotic community (A) and on the prokaryotic community without the taxa 709 Methylotenera sp. 1P/1 and 'Others' (B), respectively. The lines represent the course of the 710 treatment levels in time. Cdt stands for basic response pattern of certain treatment (d) at 711 sampling time $(\mathrm{t})$. The species weight $\left(\mathrm{b}_{\mathrm{k}}\right)$ can be interpreted as the affinity of the taxon $(\mathrm{k})$ 712 with the PRC. For clarity, only taxa with a weight higher than 0.25 or lower than -0.25 are 713 shown in A and only taxa with a weight higher than 0.5 or lower than -0.5 are shown in B. 


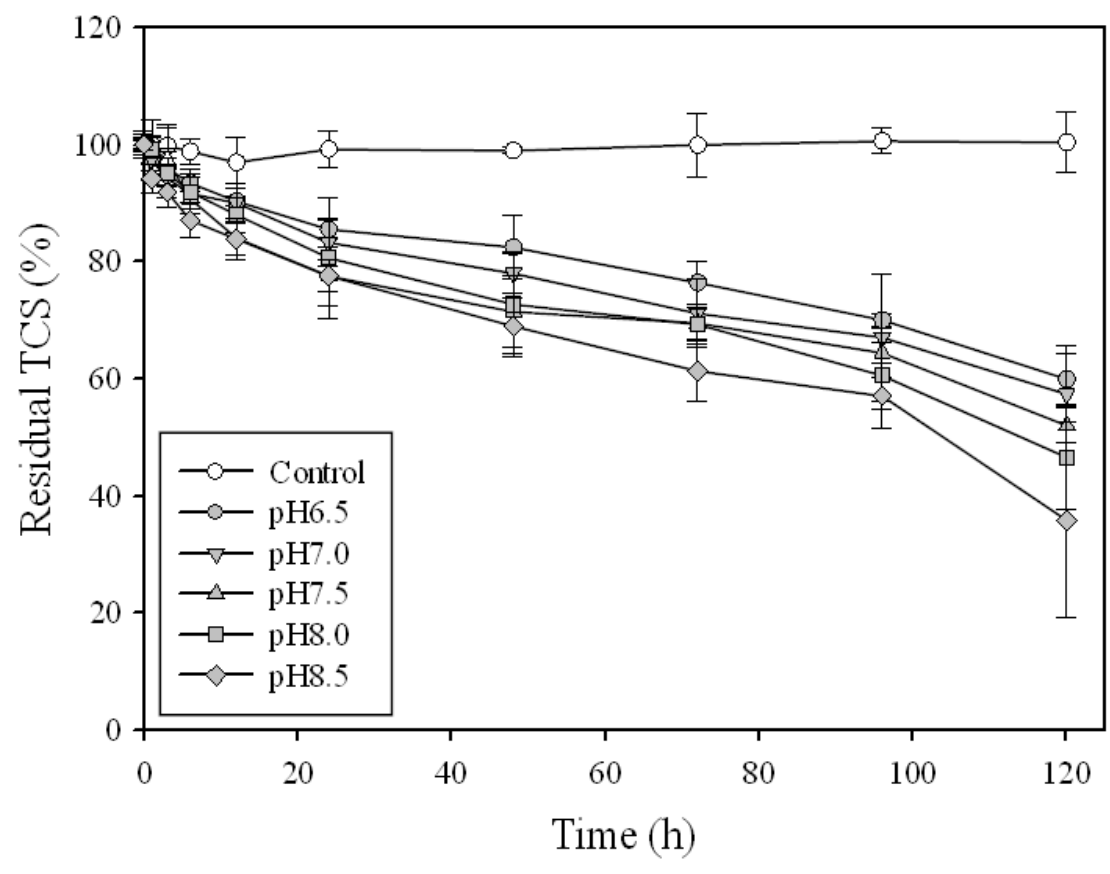

715

Figure 4 Removal of triclosan by river biofilm in artificial river water at a series of $\mathrm{pH}$ levels 